\title{
Controversial egg-producing stem cells promise better IVF
}

In the late 1990s, embryologist Jacques Cohen and his colleagues at the Saint Barnabas Medical Center in New Jersey helped a number of women with infertility problems by injecting their eggs with the cytoplasm of oocytes from young healthy donors. The idea was to rejuvenate the women's lackluster cells with extra energy-boosting mitochondria, and it worked: among 30 women who underwent the protocol, 15 successfully gave birth at the Barnabas clinic after previously failing to conceive through standard in vitro fertilization (IVF). However, ethicists cried foul about the creation of so-called 'three-parent babies'. The US Food and Drug Administration soon cracked down on the Procedure, in 2001, and human trials that the Barnabas clinic hoped to run never got off the ground.

Nearly a decade later, a twist on this strategy could soon be put to the test by a different group. A small Cambridge, Massachusettsbased startup company called OvaScience now plans to commercialize a fertility treatment that uses mitochondria from a woman's own oocyteproducing stem cells-rather than a 'third parent' - to boost the quality of mature eggs used for IVF. In the last year alone the company has raised more than $\$ 40$ million from venture capital firms; it plans to go public in the near future. Yet, despite the idea's popularity among investors, some leading reproductive biologists have questioned the existence of the stem cells upon which the technology rests.

Even those who accept the possibility of these cells express caution. "Maybe we can learn something from these cells," says Anna Veiga, scientific director of the reproductive medicine service at the Institut Universitari

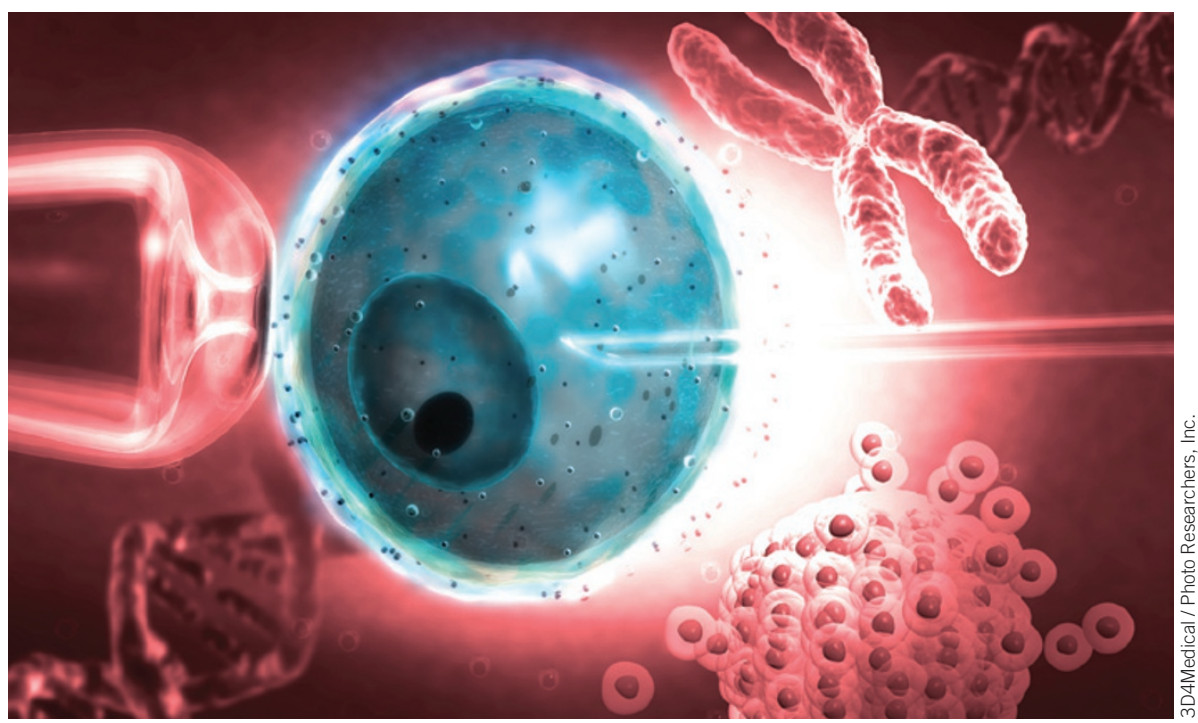

On fertile ground: Egg-producing stem cells could help infertile women conceive.
Dexeus in Barcelona, Spain. "But we have to be careful not to make statements that can bring false expectations to people who are affected by infertility."

Earlier this year, a team led by OvaScience cofounder Jonathan Tilly, a reproductive biologist at the Massachusetts General Hospital in Boston, reported in this journal that human ovaries contain a set of stem cells that can continuously give rise to immature eggs, known as oocytes, when cultured in the lab (Nat. Med. 18, 413-421, 2012). The finding-one that promised to overturn the half-century-old dogma that women are born with a limited batch of egg precursors-relied on a technique first developed by Ji Wu and her colleagues at the Shanghai Jiao Tong University in China that uses antibodies targeting a protein called DDX4 to fish out the rare cells (Nat. Cell Biol. 11, 631-636, 2009).

In July, Tilly and his colleagues also published a commentary in which they reanalyzed a recent study that traced the origins of egg cells in mice and concluded that the findings were consistent with the existence of so-called 'oogonial stem cells' (OSCs) giving rise to new oocytes (PLoS Genetics 8, e1002848, 2012). According to Ehud Shapiro, a computational and molecular biologist at the Weizmann Institute of Science in Rehovot, Israel, who led the original study, "If you adopt Occam's razor, then oocyte renewal is the simplest explanation."

\section{Believe it or not}

DDX4 is mostly found in the cytoplasm of germ cells. According to Tilly and Wu, the protein also exists on the outer surface of OSCs. But one ardent skeptic of this is Kui
Liu, a molecular reproductive biologist at the University of Gothenburg in Sweden. Liu set out to replicate the antibody-based cell-sorting approach. He couldn't. So he decided to test for the presence of these DDX4-expressing cells by creating a strain of mice with cells that glow green under normal conditions, but change to red, orange or blue whenever DDX4 is expressed. His group identified some DDX4-positive cells, yet these never divided or produced oocytes as OSCs should. "We never observed any DDX4 expression in proliferating cells from the ovary," he says. Liu's team reported the results in July in the Proceedings of the National Academy of Sciences USA (109, 12580-12585, 2012).

The inability to successfully repeat Tilly's and Wu's studies worries many onlookers. "People would like to see that others can reproduce the same phenomenon," says Hugh Clarke, a reproductive biologist at McGill University in Montreal, Canada. "Given that it is the dogma, then the standard of proof is a little bit higher." Still, it's hard to gauge whether OSCs truly exist when different teams seem to be performing different types of experiments, notes Robin Lovell-Badge, a stem cell researcher at the UK National Institute for Medical Research in London. "You have people talking cross purposes," he says. "They should be able to use the same reagents for the same experiments."

To quiet his critics, Tilly now intends to repeat and improve upon what he see as "holes and flaws" in Liu's study, and, in collaboration with Evelyn Telfer at the University of Edinburgh, derive OSCs from ovarian tissue donated by women undergoing Cesarean sections. Plus, it's full steam ahead at OvaScience, Tilly's first commercial application of his finding. Later this year, the company plans to begin a clinical study in women aged 38 to 42 who have failed two rounds of IVF and then launch the protocol commercially in 2014. "We are confident in our technology and our approach to treating female infertility," says OvaScience's chief executive Michelle Dipp.

Still, it might be some time before Tilly and OvaScience convince the field that women are not born with a limited number of egg precursors and that OSCs exist. "We're chipping away at the dogma," says Holly LaVoie, a reproductive biologist at the University of South Carolina School of Medicine in Columbia. "But there's not enough evidence to get rid of the dogma quite yet."

Elie Dolgin

Corrected after print 24 October 2012. 


\section{Correction}

In the September 2012 issue, the article entitled "Controversial egg-producing stem cells promise better IVF" (Nat. Med. 18, 1311, 2012) incorrectly stated the age range for OvaScience's first clinical trial as 35 to 42 and the anticipated time frame for commercial product launch as late 2013.

The correct age range is 38 to 42 , and the commercial product launch will be in 2014 . The errors have been corrected in the HTML and PDF versions of the article. 